\title{
CUADERNO DE TRABAJO FAMILIAS Y SOCIALIZACIÓN. VISIONES ADOLESCENTES DE REALIDADES Y DEMANDAS (2013)
}

*Docente de la Facultad de Ciencias Sociales y Educación, directora grupo Estudios de Familias, Masculinidades y Feminidades.
+Trabajadora Social. Especialista en Teorías métodos, técnicas de investigación social. Integrante del grupo de investigación: Estudios de familias masculinidades y feminidades.

'Psicóloga. Maestría en estudios de género área: mujer y desarrollo. Integrante del grupo de investigación: Estudios de familias masculinidades y feminidades.

1"Demandas de cambio sobre la maternidad y paternidad desde las paternidad desde las ciales de hijos e hijas, cocalidad Industrial de la Bahía casos Sant Lía y Cellos de Cina ceballos de "Construcción gen Construcción de las identidades en adoles centes mujeres que han estado en situación de explotación sexual en la ciudad de Cartagena de Indias. Estudios de caso desde una perspectiva de género"

Por: María del Pilar Morad Haydar*

\section{Cuaderno de Trabajo}

Serie: Familias y Dinámicas Contemporáneas

\section{FAMILIAS Y SOCIALIZACIÓN. \\ VISIONES ADOLESCENTES DE REALIDADES Y DEMANDAS}

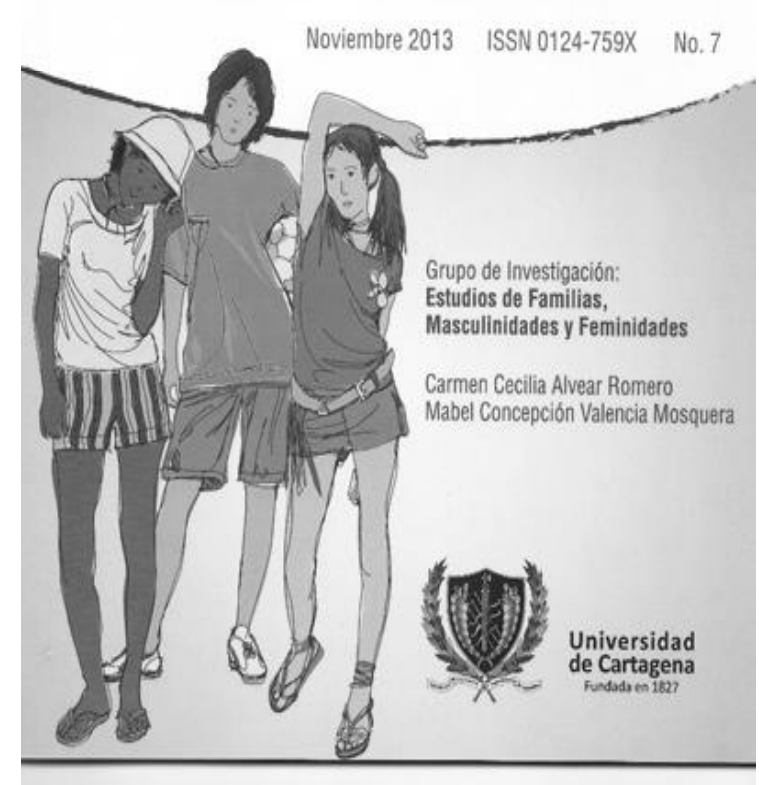

La edición de este Cuaderno de Trabajo, constituye un aporte a los temas de familias $y$ adolescencia y se fundamenta en los hallazgos de dos investigaciones ${ }^{1}$ con enfoque cualitativo, cuyas categorías centrales son familias, género, adolescencia y socialización. Su contribución es visibilizar las voces de los y las jóvenes que demandan hacia sus padres y madres un ejercicio más dialógico, con expectativas que se orienten en la construcción de relaciones equitativas, en la autoridad, sexualidad, división sexual de roles.

Los relatos expresan que las familias como contexto de socialización, enfrentan conflictos a su interior, ejerciendo posturas que son cuestionadas por los adolescentes, que van desde el autoritarismo, la coerción, hasta la negligencia, el desapego, maltrato físico y verbal, conductas que no contribuyen al desarrollo psico-social y afectivo de sus hijos(as).

Las autoras visibilizan las voces de estos actores que han estado en situación de riesgo en situación, de explotación sexual y otros jóvenes en entornos escolarizados más favorables; quienes expresan visiones en el ejercicio de la 
paternidad y maternidad que contribuye a reflexionar sobre formas culturales hegemónicas y la importancia del fortalecimiento de vínculos afectivos que les permitan asumir un contacto edificante con el mundo familiar y social. "Es deseable que padres y madres participen en términos de equidad en el ejercicio de la autoridad, y manifestaciones de afectividad" (Alvear y Valencia: 2013-37).

Sus planteamientos permiten analizar formas de socialización que vivencian los adolescente en el ejercicio del control y el respeto "el exceso de prácticas de autoridad que llevan al dominio en condiciones de violencia y maltrato, estarían en detrimento de otros aspectos importantes de las relaciones entre padres-madres e hijos e hijas, tales como el respeto, la comunicación y la misma confianza" (ibíd.: 38).

Las reflexiones que se presentan en este cuaderno de trabajo de 38 páginas, editado por la universidad de Cartagena se encamina a la construcción de niños y niñas, adolescentes hombres y mujeres con mejores potencialidades, que influyan en un contexto sociocultural donde las diferencias de género aún se naturalizan y la discriminación sigue vigente (ibídem), visionando unas relaciones innovadoras que influyan en el contexto y transformen formas hegemónicas que transcurren en la vida de las familias. 